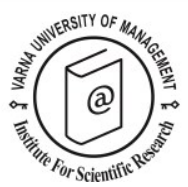

\title{
Zuelow, Eric G. E. (2015). A History of Modern Tourism. Palgrave. 304 pages (figures, bibliography, index). Price \$29.95. ISBN-13: 978-0230369658 (paperback).
}

\author{
Reviewed by Craig Webster ${ }^{1}$
}

Received: 16/05/2016

${ }^{1}$ Ball State University, Muncie, Indiana, USA; e-mail: cwebster3@bsu.edu

(C) 2017 Varna University of Management. All rights reserved

Citation Zuelow, Eric G. E. (2015). A History of Modern Tourism. Palgrave. 304 pages (figures, bibliography, index). Price \$29.95. ISBN-13: 978-0230369658 (paperback). Reviewed by Craig Webster, European Journal of Tourism Research 15, pp.175-177

Many of us who teach Tourism or tourismrelated topics have read textbooks that give a very brief overview of the history of tourism and do not think much of it, as we tend to focus on our particular specialty in tourism and are content to have a gray area in our knowledge about tourism's history. This book is welcome for many of us, as it gives us an easy and organized way to learn about tourism and its development from the Grand Tour to mass tourism. Since it is an easy read and composed of many short chapters that can be enjoyed independently and out of the context of the book, it is a useful and helpful book that can be an accommodating reference tool and teaching aid for students at nearly all levels.

The book is divided into twelve chapters, two of which are the unnumbered introduction and conclusion. The introduction explains the logic of a book clarifying how the text will give background to the evolution of tourism in the modern world. Chapters One through Ten generally deal with the development of tourism through time. The first chapter is an interesting background of early modern tourism, discussing the development of the BOOK REVIEW
Grand Tour. The second chapter gives a background to how tourism developed as something that explored and appreciated the beauty of nature. The third chapter is a look into how steam technology changed tourism by enabling more rapid and reliable forms of transport on land and on water. The fourth chapter explains the evolution of the packaging of trips. The fifth chapter shows how guidebooks developed and how this influenced the practice of tourism. The sixth chapter deals with how nationalism and imperialism played a role on the practice of tourism. The seventh chapter, and to me one of the most interesting, is about the evolution of bicycles, automobiles, and aircraft and how these technologies not only influenced our daily lives but also the practice of tourism. The eighth chapter describes the challenges and advances in tourism during the interwar years. The ninth chapter explains something about the practice of tourism following World War Two and leads to the tenth chapter on mass tourism and its development. The final chapter, the conclusion, is a short chapter that muses about the future development of tourism. 
The structure of the book generally follows a chronological logic. However, interspersed are chapters that are thematic. The thematic chapter on bicycles, automobiles, and aircraft development is especially interesting, since these technologies play such a critical role in the modern world. While many of us may know something about the development of the automobile and aircraft, few of us know much about the development of the bicycle and its development. This chapter, I found, to be one of the most interesting, giving me the opportunity to reflect upon how the development of the bicycle played a role in the creation of our modern lifestyle. Much the same could be said about the thematic chapter on guidebooks, as many of us have used guidebooks but have not really thought about how guidebooks influence the way in which we experience tourism destinations or has influenced our ways of perceiving tourism.

One of the key strengths of the book is that it is a short and easy read. While it may appear to be many pages long, there are only 184 pages of text that most people would read, since there are many references, a sizable bibliography, and an index. The large number of notes and the extensive bibliography would likely be useful to a true history fan or researcher, enabling her or him to find a good starting point for specific research on many of the topics that the author deals with in the text. The language is easy to understand and well within the vocabulary of most university students, although some first year students may struggle with some of the language when dealing with abstract concepts.

Another strength of the book is that the structure of the book allows for readers to focus upon chapters that either center attention on a time period that is the focus of a chapter or a tourism-relevant innovation that the chapter deals with. Each chapter can be read independently and there is no disadvantage to the reader if she or he reads chapters out of order or only wants to focus on one chapter.
There are some minor weaknesses in the book. While the book is attractive and has 12 illustrations/photos that make the book a bit lively, it would have been made better with some tables or data to illustrate the changes in tourism over time. For example, the author sometimes describes increases in tourism arrivals in various countries over time and the increases are impressive but when shown in a bar graph, such data are even more staggering, illustrating the massive growth of mass tourism in a short period of time. Such visual additions to the book would have illustrated the rapid rate of change in tourism development, highlighting how mass tourism and post-World War Two air travel expanded rapidly, something that leaves less of an impression when hidden inside of the text in a narrative form.

Another weakness that I see is that the conclusion is a bit superficial and short. This criticism may be a bit idiosyncratic, as I have been involved with futures research for many years, but the final chapter does not really look into the drivers that could lead to a new way of experiencing tourism in the future. Instead, the author uses somewhat of a copout, that we should "never ask an historian about the future." There are drivers that are important and obvious and I think that should have been systematically addressed such as the rise of Asian economies, climate change, resource depletion, and new technologies. But I may be guilty of blaming a historian for thinking historically.

A final weakness, for me, is that the book is a bit centered upon UK and US experiences. It is understandable that an Anglophone author would write primarily about the tourism experiences of major Anglophone countries but it would also be nice to learn more about the non-Anglophone world. For example, there is some mention of the Soviet experience with tourism. It would have been interesting to learn more about this, as the USSR was the largest country in the world and developed tourism in different ways than in the West. It would also be interesting to learn about how Japan differed from the West, since its development was rapid, 
recent, and largely modelled upon Western institutions. Despite this, it is understandable that there were to be limits in terms of what could be written about and the availability of sources in English probably dominated what is available to historians. The author, no doubt, also had to keep in mind what would be of interest to the likely readership of the book.

This is a pleasant book to read and I did enjoy reading it. What is pleasant about the book is that it is not an edited book, so the chapters fit together in ways that seem to make sense, generally, and are written by one person's writing style. This book would be useful to many researchers who need to know something about the history of tourism. This book is an easy and fun way to fill in the many gray areas those of us have on tourism history. The book is a useful and inexpensive addition to a research library or personal library that can be used as a resource for university students and researchers at all levels. 